\title{
Stages of Change for Adherence with Medication Regimens for Chronic Disease: Development and Validation of a Measure
}

\author{
Cynthia Willey, PhD, ${ }^{1}$ Colleen Redding, $P h D,{ }^{2}$ Julie Stafford, $P h D,{ }^{3}$ \\ Frances Garfield, PhD, ${ }^{4}$ Sandra Geletko, PharmD, ${ }^{1,5}$ \\ Timothy Flanigan, MD, ${ }^{6}$ Kathleen Melbourne, PharmD, ${ }^{1,7}$ \\ Jennifer Mitty, MD, ${ }^{6}$ and J. Jaime Caro, $\mathrm{MDCM}^{4,8}$ \\ ${ }^{\prime}$ College of Pharmacy, University of Rhode Island, ${ }^{2}$ Cancer Prevention Research \\ Center, University of Rhode Island, Kingston, Rhode Island, ${ }^{3}$ Bristol-Myers Squibb \\ Company, Princeton, New Jersey, ${ }^{4}$ Caro Research, Concord, Massachusetts, ${ }^{5}$ Veterans \\ Administration Medical Center, ${ }^{6}$ Division of Geographic Medicine and Clinical \\ Immunology, The Miriam Hospital and Brown University School of Medicine, ${ }^{7}$ Coastal \\ Medical Center, Providence, Rhode Island, and ${ }^{8}$ Division of General Internal Medicine, \\ McGill University, Montreal, Quebec, Canada
}

\begin{abstract}
Background: The stages-of-change (SOC) model has been used to explain and predict how behavior change occurs, but it is new as an approach to understanding why patients fail to take their medications as prescribed.

Objective: This study validated a 2 -item measure of SOC for adherence with medication regimens in 2 groups of patients prescribed pharmacologic therapy for chronic conditions.

Methods: Two cross-sectional studies of attitudes toward medication adherence included the same measure of SOC for medication adherence. One was a sample of 161 HIV-positive patients in the United States, and the other was an international sample of 731 patients with hypertension. The validity of the measure of SOC for medication adherence was examined in both convenience samples using previously validated self-reported measures of adherence (the Medication Adherence Scale and a measure of adherence from the Medical Outcomes Study), and in the HIV samplc using clectronic monitoring of adherence behavior in 85 patients.

Results: Construct validity was demonstrated in both samples by associations between SOC and the previously validated measures of adherence $(P<0.001)$, and predictive validity was supported by significant associations between SOC for medication adherence and electronically monitored medication-taking behavior during the next 30 days $(P<0.03)$.
\end{abstract}

Accepted for publication June 1, 2000.

Printed in the USA. Reproduction in whole or part is not permitted. 


\section{WILLEY ET AL.}

Conclusions: Behavior-change theory suggests that stage-tailored communication strategies are more effective than uniform health-promotion messages. Our results provide a foundation for the development of interventions for medication adherence that are tailored to patients' readiness for change. Our validated 2 -item measure of SOC for medication adherence can be used to match communication strategies to individual motivation and readiness for adherence with chronic disease medication regimens.

Key words: medication adherence, compliance, HIV, hypertension, stages of change, Medication Event Monitoring System. (Clin Ther. 2000;22:858-871)

\section{INTRODUCTION}

Over 1.5 billion prescription drugs are dispensed each year, and it has been suggested that $\sim 50 \%$ of patients fail to take their medications as prescribed. ${ }^{1-6}$ Nonadherence with medication regimens leads to suboptimal outcomes and higher health care costs, and can bias the results of clinical trials and outcomes research. ${ }^{7-9}$ The literature on noncompliance with medication is extensive, but 1 review found that fundamental knowledge about noncompliance and effective strategies for enhancing compliance had changed little since $1980 .^{10}$

One issue that has not been explored extensively in the literature is the distinction between unintentional and intentional noncompliance. ${ }^{10}$ At one time or another, most patients make unintentional errors in taking medications, usually because of forgetfulness or misunderstanding of instructions. However, the literature suggests that intentional noncompliance is also a significant problem, particularly among patients with chronic disorders requiring long-term therapy, such as asthma, hypertension, HIV infection, and diabetes. ${ }^{4-6.11}$ In a study of medications prescribed for chronic obstructive pulmonary disease, the most prevalent reason given for missing medications in the previous month was "felt good and decided not to dose." 12 In a study of noncompliance with zidovudine therapy, reasons for refusal of treatment included "fear of side effects" and belief that the treatment "was not necessary." 13 The results of these and other studies suggest that the adoption of medication adherence requires intentional behavior change.

\section{The Stages-of-Change Model of Behavior Change}

The transtheoretical model of change, or stages-of-change (SOC) model, has been particularly effective in helping to understand how individuals change their behavior. ${ }^{14}$ Table I summarizes the stages through which individuals progress as they change their behavior and the stagematched strategies that predict progress to each subsequent stage. Five stages of change have been identified: precontemplation (not considering changing behavior in the next 6 months), contemplation (considering changing behavior in the next 6 months), preparation (planning to change behavior during the next month), action (currently changing behavior), and maintenance (successful behavior change for $\geq 6$ months).

The SOC model has been used to identify stages of change in the adoption of positive health behaviors and the cessation of negative health behaviors, including reduction of fat in the diet, ${ }^{15}$ smoking cessation, ${ }^{16-18}$ participation in mammography screening, ${ }^{19}$ and adoption of exercise, ${ }^{20}$ sun 
CLINICAL THERAPEUTICS

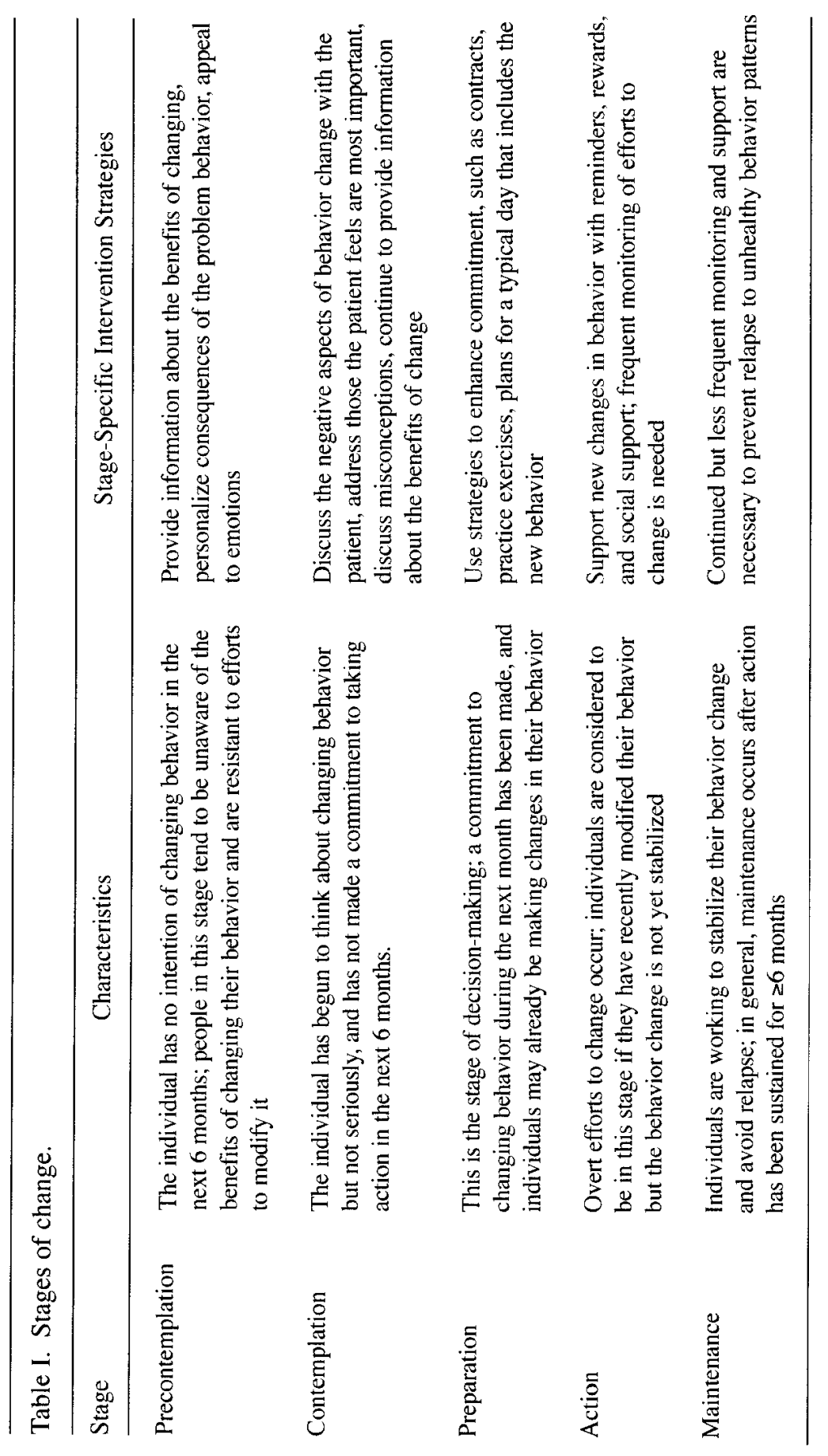


protection, ${ }^{21}$ and condom use. ${ }^{22}$ This model has also been applied to change in complex health behaviors such as the diet, exercise, and glucose monitoring changes required for diabetes self-management. ${ }^{23,24}$ One considerable advantage of the SOC model is that behavior-change interventions tailored to current readiness to change have been shown to be more effective than interventions using a single health-education message. ${ }^{25-30}$

The SOC model has not yet been tested as an approach to enhancing adherence with medication. The purpose of the present study was to develop a method for measuring SOC for adherence with medication regimens prescribed for chronic conditions. We examined the construct validity of SOC for medication adherence using previously validated self-reported measures of adherence in 2 groups of patients prescribed medication for chronic conditions (HIV and hypertension). We studied predictive validity using electronic monitoring of medication-taking behavior in a subset of HIV-positive patients.

\section{PATIENTS AND METHODS}

\section{Sample 1}

The primary purpose of study 1 was to develop measures of SOC for medication adherence and measures of related transtheoretical model constructs, such as decisional balance and processes of change. The sample consisted of patients currently prescribed medication for HIV. Eligibility criteria included age between 18 and 74 years, a current prescription for approved protease inhibitors (saquinavir, ritonavir, nelfinavir, or indinavir), ability to read English, and positive HIV status. Subjects were recruited in 1994 during non-acute care visits to 3 sites that provide primary HIV medical care and support services to $>75 \%$ of the HIV-infected persons in Rhode Island. Approximately $18 \%$ of patients at the target sites had a CD4+ count of $<200$ cells $/ \mathrm{mm}^{3}, 56 \%$ had a CD $4+$ count between 200 and 500 cells $/ \mathrm{mm}^{3}$, and $28 \%$ had a CD4+ count of $>500$ cells $/ \mathrm{mm}^{3}$. Approximately $44 \%$ of the patients had peripheral viral loads below detectable limits $(<500$ copies/mL). Protease inhibitors were new to the market at the time of data collection, and all patients were new users of these drugs.

\section{Procedure}

Physicians informed eligible patients of the opportunity to participate in a study of attitudes about medications. They were offered a $\$ 20$ gift certificate for participation, and $\sim 95 \%$ of patients attending the participating clinics agreed to take part. Research assistants were licensed pharmacists or senior-level pharmacy students. The research assistants explained the purpose of the study, emphasized its confidentiality, and obtained written consent using forms approved by the University of Rhode Island institutional review board (IRB) and the IRBs of all the clinical study sites. Questionnaires were administered in a private setting and required $\sim 1.5$ hours to complete. Color-scanned images of all antiretroviral medications were uscd to assist patients in recalling the names of medications while filling out the questionnaire.

After completion of the questionnaire, a subset of patients were randomly selected to receive a 30 -day supply of their prescribed protease inhibitor in a vial with a Medication Event Monitoring System (MEMS) TrackCap ${ }^{\text {TM }}$ (APREX Corporation, Union City, California). A second appointment was scheduled for 1 month 
later, and data from the MEMS TrackCap were read using a MEMS-4 Communicator. Selected patients were offered a $\$ 50$ gift certificate for their participation, and $\sim 90 \%$ agreed to take part.

\section{Sample 2}

Patients with a diagnosis of hypertension were recruited from 5 countries (United States, Canada, France, Germany, and Italy) for a survey on attitudes toward medication compliance conducted by Bristol-Myers Squibb Company, Princeton, New Jersey, and Sanofi Pharma, Paris, France. Questions designed to measure behavior-change constructs were added to the questionnaire to support a University of Rhode Island sabbatical project on SOC for medication adherence.

All patients were volunteers who responded to recruitment efforts. The sample was essentially a convenience sample, although distribution of the sample across countries was designed to be roughly proportional to population size. Two-stage cluster sampling was employed within each country to provide geographic representation (25 sites in the United States, $\sim 15$ in other countries). Quota sampling, based on self-reported compliance, was used to ensure an adequate distribution of those who were noncompliant with prescribcd thcrapy. Individuals who were prescribed medication but had never taken it $(17 \%)$, those who had discontinued their medication $(22 \%)$, and those who were partially compliant $(27 \%)$ were oversampled to ensure an adequate distribution. Only $34 \%$ of the sample reported taking their medication exactly as prescribed.

Patients were identified primarily through physicians, pharmacists, patient networks, and newspaper advertisements.
Professional recruiters contacted each patient to determine eligibility. Eligible patients were required to have been prescribed an antihypertensive agent from 3 to 18 months before the interview and to have been diagnosed with hypertension in 1992 or later. They must never have been diagnosed with or treated for angina, ischemic heart disease, arrhythmia, arteriosclerosis, myocardial infarction, or stroke, and must never have undergone cardiac bypass surgery or angioplasty.

The most commonly prescribed antihypertensive medications taken by study participants were angiotensin-converting enzyme inhibitors $(28 \%)$, beta-blockers (21\%), calcium channel inhibitors (18\%), and diuretics $(16 \%)$. The majority of patients $(89 \%)$ were reimbursed for their medication costs.

\section{Procedure}

Trained interviewers explained that the study's purpose was to understand attitudes about high blood pressure and that all answers would be confidential. All patients gave written informed consent, and all datacollection procedures followed the Code of Standards and Ethics for Survey Research developed by the Council of American Survey Research Organizations. ${ }^{31}$ The questionnaire was administered in a 1-on-1 interview session at a research facility, the interviewer's home, or the patient's home. The interviewer reviewed instructions for cach section of the questionnaire and was available to answer questions as the patient completed the form.

\section{Measures}

Stage of Change

Questions that have been used to measure SOC in previous applications of the 


\section{WILLEY ET AL.}

Table II. Questions used to assess stage of change for medication adherence.

1. People sometimes find it difficult to take their medication as directed by their physician. As directed means consistently taking the amount of medication prescribed by your physician at the time(s) prescribed by your physician. Please find the statement that best describes the way you feel right now about taking your (high blood pressure/protease inhibitor) medication as directed.

$\Lambda$. No, I do not take and right now am not considering taking my (high blood pressure/ protease inhibitor) medication as directed. (Precontemplation)

B. No, I do not take but right now am considering taking my (high blood pressure/protease inhibitor) medication as directed. (Contemplation)

C. No, I do not take but am planning to start taking my (high blood pressure/protease inhibitor) medication as directed. (Preparation)

D. Yes, right now I consistently take my (high blood pressure/protease inhibitor) medication as directed.

If the answer to question 1 is $D$, then ask:

2. How long have you been taking your (high blood pressure/protease inhibitor) medication as directed?

A. $\leq 3$ months

B. $>3$ months to 6 months

C. $>6$ months to 12 months

D. $>12$ months

If the answer to question $\mathrm{I}$ is $\mathrm{D}$ and the answer to question 2 is $\mathrm{A}$ or $\mathrm{B}$, then the stage of change is action. If the answer to question 1 is $\mathrm{D}$ and the answer to question 2 is $\mathrm{C}$ or $\mathrm{D}$, then the stage of change is maintenance.

model $^{18,32}$ were modified to describe medication adherence (Table II). Patients in sample 1 (HIV) were asked about their SOC for adherence with protease inhibitors, and patients in sample 2 (hypertension) were asked about their SOC for adherence with antihypertensive medication.

\section{Self-Reported Adherence}

The Medication Adherence Scalc (MAS), ${ }^{33}$ a previously validated measure of compliance, was included in the survey given to HIV-positive patients. The MAS contains 4 questions that are answered "yes" or "no" (Table III). A positive response to any question indicates a problem with adherence. The total score ranges from 1 to 4 , with a higher score indicating poorer adherence. A 1-item Likert-scaled measure of medication adherence from the Medical Outcomes Study (MOS) ${ }^{34}$ was used in the survey given to antihypertensive patients. This item was part of a 4-item scale used to measure disease-specific adherence for hypertension. The other 3 items measured other adherence bchaviors, such as following a low-salt diet, following a low-fat diet, and exercising regularly. The wording of the question was "How often have you taken your prescribed medication in the past 4 weeks?" and the 6 possible responses were none of the time, a little of the time, some of the time, a good bit of the time, most of the time, and all of the time. Categories 5 and 6 were combined, since patients who reported adherence most or all 
CLINICAL THERAPEUTICS ${ }^{\text {tin }}$

Table III. The Medication Adherence Scale. ${ }^{33}$

The response options are "yes" and "no," and the maximum score is 4 .

During the last 3 months, have you ever stopped taking this medication because you felt better or worse?

During the last 3 months, have you cver forgotten to take this medication?

During the last 3 months, have you at times been careless about taking this medication?

During the last 3 months, have you ever taken less of this medication than your doctor prescribed because you felt better or worse?

of the time were considered adherent with medication.

\section{Electronically Monitored Medication Compliance}

The MEMS TrackCap records the time and date of every opening of the MEMS vial. The benefits of electronic monitoring are extensive: these devices provide data on the interval between doses and thus can reveal patterns of nonadherence or "drug holidays." ${ }^{35}$ However, because the TrackCap records only the time and date of opening, it has the disadvantage that multiple doses can be removed at 1 time. Patients were given a calendar page and asked to record occasions when $>1$ dose was removed from the vial and the additional doses were taken later in the day. The calendar page and electronic monitoring data were combined to calculate the proportion of total prescribed doses of protease inhibitors taken during 30 days of adherence monitoring.

\section{Statistical Analyses}

Descriptive statistics were used to characterize demographic variables and SOC for medication adherence. Construct validity of the SOC measure was examined by comparing SOC with scores on the MAS and the MOS measure of adherence. A 1way analysis of variance was performed to determine whether mean scores on the MAS differed by SOC for adherence. ${ }^{36}$ The Bonferroni multiple-comparison procedure was used to identify which pairs of means were significantly different. ${ }^{36}$ The chisquare statistic was used to examine the association between SOC for adherence and the MOS measure of adherence.

Validity of the SOC measure was tested by comparing patients' self-reported $\mathrm{SOC}$ at baseline with the percentage of total prescribed doses taken during the subsequent 30 days of electronic monitoring. One-way analysis of variance was used to determine whether the mean number of doses recorded electronically varied by SOC for adherence at baseline, and the Bonferroni multiple-comparison procedure was used to identify which pairs of means were significantly different. ${ }^{36}$

\section{RESULTS}

Demographic and baseline characteristics of the 2 samples are given in Table IV. The HIV-positive sample $(\mathrm{N}=161)$ was predominantly male, with a mean age of 39.6 years, and the sample of hyperten- 
C. WILLEY ET AL.

Table IV. Characteristics of the 2 samples.

\begin{tabular}{lcc}
\hline Characteristic & $\begin{array}{c}\text { HIV-Positive Sample } \\
(\mathrm{N}=161)\end{array}$ & $\begin{array}{c}\text { Hypertensive Sample } \\
(\mathrm{N}=731)\end{array}$ \\
\hline Age (y), mean \pm SD & $39.6 \pm 7.4$ & $56.6 \pm 12.5$ \\
Sex (\%) & & \\
Male & 83.0 & 45.0 \\
Female & 17.0 & 55.0 \\
Race (\%) & & \\
White & 78.9 & 94.9 \\
African American & 7.2 & 3.2 \\
Hispanic & 3.9 & 1.3 \\
Other & 10.0 & 0.6 \\
High school cducation or morc $(\%)$ & 84.1 & 67.6 \\
Health perceived as poor/fair $(\%)$ & 13.1 & 23.4 \\
Stage of change for adherence with & & \\
medication (\%) & & 28.8 \\
Precontemplation & 1.3 & 19.8 \\
Contemplation & 5.7 & 11.9 \\
Preparation & 8.2 & 6.8 \\
Action & 44.0 & 31.1 \\
Maintenance & 40.9 & \\
\hline
\end{tabular}

sive patients $(\mathrm{N}=731)$ was international (United States 200, Canada 97, France 133 , Germany 151 , Italy 150 ), predominantly female, and had a higher mean age.

The HIV-positive sample was skewed toward the action and maintenance stages $-7.0 \%$ were in the precontemplation or contemplation stages, and $44.0 \%$ were in the action stage, perhaps because protease inhibitors were new to the market. Because the data were collected in clinical settings, they may have included patients more inclined to be adherent than would be found in a reference population. Because of the small proportion of individuals in the precontemplation and contemplation stages, these categories were combined in subsequent analyses.
The distribution of SOC in the sample of patients taking antihypertensive medication was bimodal, with the largest proportion of individuals in the precontemplation (28.8\%) and maintenance (31.5\%) slages. Thuse in the action stage were the smallest group in this sample $(6.8 \%)$, and only $11.9 \%$ were in the preparation stage.

The validity of SOC for medication adherence was examined using 2 different self-reported measures and electronic monitoring of adherence behavior (Table V). A 1-way analysis of variance of the MAS by SOC for adherence with protease inhibitors showed significant differences by stage $(F=7.46, P<0.001)$. The MOS adherence measure was strongly associated with SOC for adherence with antihy- 
Table V. Associations between stage of change for adherence and other measures of adherence. ${ }^{*}$

\begin{tabular}{|c|c|c|c|}
\hline \multirow[b]{2}{*}{ Stage of Change } & \multicolumn{2}{|c|}{ Protease-Inhibitor Therapy } & \multirow{2}{*}{$\begin{array}{c}\text { Antihypertensive } \\
\text { Medication }\end{array}$} \\
\hline & $\begin{array}{c}\text { MAS Score, } \\
\text { Mean } \pm \text { SE (no.) } \\
(n=161)\end{array}$ & $\begin{array}{l}\% \text { of Doses Taken, } \\
\text { Mean } \pm \text { SE (no. })^{\dagger} \\
(\mathrm{n}=85)\end{array}$ & \\
\hline \multicolumn{4}{|l|}{ Precontemplation/ } \\
\hline Preparation (PREP) & $1.73 \pm 0.04(11)$ & $64.2 \pm 2.65$ & $52.3 \pm 0.03(86)$ \\
\hline Action (A) & $0.61 \pm 0.06(67)$ & $86.5 \pm 2.23(31)$ & $95.9 \pm 0.01(49)$ \\
\hline \multirow[t]{2}{*}{ Maintenance (M) } & $0.81 \pm 0.08(64)$ & $86.9 \pm 1.67(41)$ & $96.9 \pm 0.00(226)$ \\
\hline & $F=7.46, P<0.001$ & $F=2.95, P=0.03$ & $\chi^{2}=441.3, P<0.001$ \\
\hline $\begin{array}{l}\text { Significant mean } \\
\text { differences }\end{array}$ & $\begin{array}{l}\text { PREP-M } \\
\text { PC/C-PREP } \\
\text { PC/C-M } \\
\text { PC/C-A } \\
\text { PREP-A }\end{array}$ & $\begin{array}{l}\mathrm{PC} / \mathrm{C}-\mathrm{M} \\
\mathrm{PC} / \mathrm{C}-\mathrm{A} \\
\text { PREP-A } \\
\text { PREP-M }\end{array}$ & \\
\hline
\end{tabular}

MAS $=$ Medication Adherence Scale.

*Analyses included only those patients with no missing data.

${ }^{\dagger}$ Measured using the Medication Event Monitoring System (APREX Corporation, Union City, California).

¥The Medical Outcomes Study measure of adherence. ${ }^{34}$

pertensive medication $(P=0.001)$. Only $7.0 \%$ of those in precontemplation for adherence with antihypertensive medication responded that they were adherent with their medication regimen "most or all of the time," compared with $96.9 \%$ of those in the maintenance stage.

Table $\mathrm{V}$ also demonstrates that SOC predicts adherence with medication as measured by an objective indicator of doses taken (MEMS, $n=85$ ). One-way analysis of variance showed a statistically significant assaciation between baseline SOC for adherence and adherence with protease inhibitor therapy during the next
30 days $(P=0.03)$, as measured by electronic monitoring of doses (MEMS).

\section{DISCUSSION}

A patient who receives a prescription for a medication to be taken on a long-term basis is essentially instructed to adopt a new lifestyle. Behavior-change theory suggests that patients vary in their readiness to adopt a new behavior and that strategies for encouraging behavior change should be tailored to "readiness for change." The premise of basing interventions on an individual's stage of 


\section{WILLEY ET AL.}

change is that behavior change is best encouraged in small steps. The objective of each contact is to move to the next stage of change rather than encouraging immediate action. The SOC theory suggests that rewards, monitoring devices, and reminder techniques are most useful for individuals who are in the action and maintenance stages, but individuals in earlier stages need consciousness-raising interventions that focus on awareness of the benefits of therapy. ${ }^{37,38}$

Several authors have suggested that the efficacy of medication-adherence interventions might be improved by applying the SOC theory of behavior change. ${ }^{39-41} \mathrm{De}-$ velopment of valid measures for assessing SOC for medication adherence is the first step toward designing stage-matched interventions targeted at adherence. The construct validity of the measure of SOC for adherence with medication in this study was supported by significant linear associations with previously validated measures, the MAS and the MOS adherence measure. We also demonstrated predictive validity using electronic monitoring of medication adherence in addition to self-reporting. The literature consistently indicates that most selfreported measures overestimate medication adherence by as much as $100 \%,{ }^{35,42,43}$ but electronic monitoring provides an unobtrusive and objective measure compared with pill counts or serum levels. ${ }^{35}$ Our results showed that SOC for adherence prospectively predicted the results of electronic monitoring of doses of protease-inhibitor therapy in a validation subsample of 85 HIVpositive patients.

Interventions based on SOC often include individualized information on the pros and cons of adopting a new behavior. This strategy is most useful in interactions targeting individuals in the early stages of change, since scores on measures of pros and cons predict movement out of the precontemplation stage. ${ }^{44} \mathrm{Al}$ though health care providers are acutely aware of the benefits of adopting adherent behavior (eg, reduction of symptoms, lower risk of complications), the prevalence of noncompliance with medication suggests that for many patients, the negative aspects of long-term medication adherence (eg, minor side effects, being reminded of their illness or condition) often outweigh the benefits. The pros and cons of adherence with specific medication regimens vary according to the relevant sideeffect profile, complexity of the regimen, degree of symptomatic relief, and many other factors. ${ }^{45}$ Therefore, applications of the SOC theory that employ a generic stage-tailored approach may not be as effective as intervention strategies that take into account the unique pros and cons of adherence with a specific regimen.

For example, providers of care for HIVpositive patients could encourage open discussion of fears about side effects with patients in the precontemplation and contemplation stages of change. Patients with hypertension who are in the precontemplation or contemplation stages may need information about the benefits of adherence, such as prevention of stroke or heart attack, and the feeling of being actively engaged in protecting their health. Health care providers may sometimes assume that patients are familiar with these benefits when, in fact, they are not. For many patients with hypertension, the cons associated with minor side effects may be more compelling than the pros of longterm therapy. The primary goal of interactions with early-stage patients is to shift their attention from focusing on the negative aspects of therapy to a more bal- 
anced view of both the benefits and costs of therapy.

However, discussing pros and cons of adherence with patients who are ready for action or are in the maintenance stage may in fact be counterproductive. ${ }^{44,46}$ These patients are no longer focused on thinking about changing their behavior but are actively modifying it. Patients in the later stages of change still need assistance with adherence; we found an average adherence of $86 \%$ among HIV-positive patients in the maintenance stage of adherence, which may not be adequate for virologic success. ${ }^{47}$ The SOC theory suggests that behavioral strategies for change, such as reminders, rewards, and support from others, are appropriate strategies for patients in the action or maintenance stages of change. ${ }^{48-51}$

\section{Study Limitations}

Limitations of this study include the small numbers of individuals in the early stages of change for adherence with HIV medication. Although this reduced the study's power to detect differences, the results of statistical tests were significant, attesting to the strength of the effects observed. Also, because of the time and expense associated with the use of electronic monitoring devices, we examined the predictive validity of SOC for medication adherence by electronically monitoring only 1 type of medication for only 1 month. The samples studicd werc not representative population-based samples and should be viewed as convenience samples used for validation purposes. Although it is unlikely that selection bias could explain the concordance between SOC for medication adherence and other adherence measures in individual patients, attempts to replicate these findings should be carried out in diverse patient groups with longer follow-up and other medication regimens in population-based samples.

These measures were self-administered in private settings, and their use by clinicians may be more subject to social desirability bias (ie, underreporting of such socially undesirable responses as noncompliance) than our results indicate. However, health care providers can assess SOC for adherence in less direct ways. For example, the provider might ask if a patient feels ready to begin the medication regimen and understands the benefits of therapy. If the patient is not sure, this is an indication that he or she may be in an earlier stage of readiness for medication adherence, calling for further exploration of attitudes about the pros and cons of adherence.

\section{CONCLUSIONS}

Behavior-change theory suggests that tailored intervention strategies are more effective than uniform health-promotion messages. Our results provide a valid 2 -item measure of SOC for medication adherence that can serve as a foundation for medication-adherence interventions tailored to readiness for change. This measure can be used to identify many patients with potential adherence problems and to match communication strategies to individual motivation and readiness for adherence with chronic disease medication regimens.

\section{ACKNOWLEDGMENTS}

This study was supported by National Institute on Drug Abuse grant R03DA09942 and by Bristol-Myers Squibb Company, Princeton, New Jersey, and Sanofi Pharma, Paris, France. 


\section{WILLEY ET AL.}

The authors acknowledge the extensive contributions of Sarah Chase, who performed data analyses, Brian Moss, who coordinated international data collection and data management, and Kathleen Hayes, who assisted with manuscript preparation. They also acknowledge the contributions of Gwendolyn Holtzinger and Alexandra Ward, who assisted in recruiting and interviewing study participants.

Address correspondence to: Cynthia Willey, PhD, Department of Applied Pharmaceutical Sciences, College of Pharmacy, University of Rhode Island, 41 Lower College Road, Kingston, RI 02881 .

\section{REFERENCES}

1. Sackett DL, Snow IC. The magnitude of compliance and non-compliance. In: Haynes RB, Taylor DW, Sackett DL, eds. Compliance in Health Care. Baltimore: Johns Hopkins University Press; 1979: 11-22.

2. Stewart RB, Cluff LE. A review of medication errors and compliance in ambulant patients. Clin Pharmacol Ther. 1972;13: $463-468$.

3. Jay S, Litt IF, Durant RH. Compliance with therapeutic regimens. I Adolesc Health Care. 1984;5:124-136.

4. Mallion JM, Baguet JP, Siche JP, et al. Compliance, electronic monitoring and antihypertensive drugs. J Hypertens Suppl. 1998;16:S75-S79.

5. Flack JM, Novikov SV, Ferrario CM. Benefits of adherence to anti-hypertensive drug therapy. Eur Heart J. 1996;17(Suppl A): $16-20$.
6. Feldman R, Bacher M, Campbell N, et al. Adherence to pharmacologic management of hypertension. Can J Public Health. 1998;89:I16-I18.

7. Vanhove GF, Schapiro JM, Winters MA, et al. Patient compliance and drug failure in protease inhibitor monotherapy. JAMA. 1996;276:1955-1956. Letter.

8. Carpenter CC, Fischl MA, Hammer SM, et al. Antiretroviral therapy for HIV infection in 1997. Updated recommendations of the International AIDS Society-USA Panel. JAMA. 1997;277:1962-1969.

9. Becker MH. Patient adherence to prescribed therapies. Med Care. 1985;23:539-555.

10. Dunbar-Jacobs J, Dunning EJ. Compliance with antilypertensive regimens: $A$ review of research in the 1980's. Ann Behav Med. 1991;13:30-39.

11. Morris LS, Schulz RM. Patient compliance: An overview. J Clin Pharm Ther. 1992;17:283-295.

12. Dolce JJ, Crisp C, Manzella B, et al. Medication adherence patterns in chronic obstructive pulmonary disease. Chest. 1991; 99:837-841.

13. Samet JH, Libman H, Steger KA, et al, Compliance with zidovudine therapy in patients infected with human immunodeficiency virus, type 1: A cross-sectional study in a municipal hospital clinic. Am J Med. 1992;92:495-502.

14. Prochaska JO. Assessing how people change. Cancer. 1991;67(Suppl 3):805-807.

15. Greene GW, Rossi SR, Reed GR, et al. Stages of change for reducing dietary fat to $30 \%$ of energy or less. J Am Diet Assoc. 1994;94:1105-1110; quiz 1111-1112. 
16. Rossi JS. Stages of change for 15 health risk behaviors in an HMO population. Annu Proc Soc Behav Med. 1992;13:132. Abstract.

17. Prochaska JO, Velicer WF, Rossi JS, et al. Stages of change and decisional balance for 12 problem behaviors. Health Psychol. 1994;13:39-46.

18. Prochaska JO, DiClemente CC. Stages and processes of self-change of smoking: Toward an integrative model of change. J Consult Clin Psychol. 1983;51:390-395.

19. Rakowski W, Fulton JP, Feldman JP. Women's decision making about mammography: A replication of the relationship between stages of adoption and decisional balance. Health Psychol. 1993;12:209-214.

20. Marcus BH, Simkin LR. The transtheoretical model: Applications to exercise behavior. Med Sci Sports Exerc. 1994;26: 1400-1404.

21. Rossi JS, Blais LM, Weinstock MA. The Rhode Island Sun Smart Project: Skin cancer prevention reaches the beaches. Am J Public Health. 1994;84:672-674.

22. Redding CA, Rossi JS. Testing a model of situational self-efficacy for safer sex among college students: Stage and gender-based differences. Psychol Health. 1999; 14:467-486.

23. Ruggiero LP, Prochaska JO. Readiness for change: Applications of the transtheoretical model to diabetes. Diabetes Spectrum. 1993;6:21-60.

24. Ruggiero L, Glasgow R, Dryfoos JM, et al. Diabetes self-management. Self-reported recommendations and patterns in a large population. Diabetes Care. 1997; 20:568-576.
25. Marcus BH, Owen N, Forsyth LH, et al. Physical activity interventions using mass media, print media, and information technology. Am J Prev Med. 1998;15:362-378.

26. Rossi JS, Blais LM, Redding CA, Weinstock MA. Preventing skin cancer through behavior change. Implications for interventions. Dermatol Clin. 1995;13:613-622.

27. Campbell MK, DeVellis BM, Strecher VJ, et al. Improving dietary behavior: The effectiveness of tailored messages in primary care settings. Am J Public Health. 1994;84:783-787.

28. Rakowski W, Ehrich B, Goldstein MG, et al. Increasing mammography among women aged $40-74$ by use of a stagematched, tailored intervention. Prev Med. 1998;27:748-756.

29. Velicer WF, Prochaska JO, Fava JL, et al. Intcractive versus noninteractive interventions and dose-response relationships for stage-matched smoking cessation programs in a managed care setting. Health Psychol. 1999;18:21-28.

30. Skinner CS, Strecher VJ, Hospers H. Physicians' recommendations for mammography: Do tailored messages make a differcnce? Am J Public Health. 1994;84:43-49.

31. Available at: www.casro.org/casro.htm.

32. Marcus BH, Selby VC, Niaura RS, Rossi JS. Self-efficacy and the stages of exercise behavior change. Res $Q$ Exerc Sport. 1992;63:60-66.

33. Brooks CM, Richards JM, Kohler CL, et al. Assessing adherence to asthma medication and inhaler regimens: A psychometric analysis of adult self-report scales. Med Care. 1994;32:298-307.

34. Sherbourne CD, Hays RD, Ordway L, et al. Antecedents of adherence to medical 
C. WILLEY ET AL.

recommendations: Results from the Medical Outcomes Study. J Behav Med. $1992 ; 15: 447-468$.

35. Urquhart J, De Klerk E. Contending paradigms for the interpretation of data on patient compliance with therapeutic drug regimens. Stat Med. 1998;17:251-267; discussion 387-389.

36. Kleinbaum DK, Kupper LL. Applied Regression Analysis and Other Multivariable Methods. North Scituate, Mass: Duxbury Press; 1978.

37. Velicer WF, Prochaska JO, Bellis JM, et al. An expert system intervention for smoking cessation. Addict Behav. 1993;18:269-290.

38. Willey C, Laforge R, Blais L, et al. Public health and the science of behavior change. Curr Issues Public Health. 1996; 2:18-25.

39. Lyons C. HIV drug adherence: Special situations. J Assoc Nurses AIDS Care. 1997; 8(Suppl):29-36.

40. Keller S. Implications of the stages of change model for medication compliance. Eur Respir Rev. 1998;8:260-266.

41. Grilo C. An alternative perspective regarding "Noncompliance: What to Do?" Behavior Therapist. 1993;16:219-220.

42. Rudd P, Ahmed S, Zachary V, et al. Issues in patient compliance: The search for therapeutic sufficiency. Cardiology. 1992;80 (Suppl 1):2-10.

43. Cramer JA, Mattson RH, Prevey ML, et al. How often is medication taken as prescribed? A novel assessment technique [published correction appears in JAMA 1989;262:1472]. JAMA. 1989;261:3273-3277.

44. Redding CA, Rossi JS, Rossi SR, et al. Health behavior models. In: Travis JW,
Hyner GC, Peterson KW, et al., eds. SPM Handbook of Health Assessment Tools. Pittsburgh, Pa: Society of Prospective Medicine and Institute for Health and Productivity Management; 1999:83-93.

45. Willey C, Redding CA, Stafford J, et al. Stages of change for adherence with medication. Ann Behav Med. 1999;21:S156. Abstract.

46. Velicer WFD, DiClemente CC. Understanding and intervening with the total population of smokers. Tob Control. 1993;2:95-96.

47. Paterson D, Swindells S, Mohr J, et al. How much adherence is enough? A prospective study of adherence to protease inhibitor therapy using MEMSCaps. Presented at Seventh Conference on Retroviruses and Opportunistic Infections; January 30-February 2, 2000; Chicago, Illinois.

48. Marcus BH. Exercise behavior and strategies for intervention. Res $Q$ Exerc Sport. 1995;66:319-323.

49. Prochaska JO. What causes people to change from unhealthy to health enhancing behavior? In: Cummings CC, Floyd JD, eds. Human Behavior and Cancer Risk Reduction: Overview and Report of a Conference on Unmet Research Needs. Atlanta, Ga: American Cancer Society; 1989.

50. Rossi JS. Common processes of change across nine problem behaviors. Presented at the 100th Annual Convention of the American Psychological Association: August 14-18, 1992; Washington DC.

51. Prochaska JO, DiClemente CC. Common processes of change for smoking, weight control, and psychological distress. In: Shiffman S, Wills T, eds. Coping and Substance Abuse. New York: Academic Press; 1985:345-364. 